\title{
PRODUCCIÓN DE ALIMENTO VIVO PARA LA INVESTIGACIÓN EN ACUICULTURA DE PECES MARINOS EN LA UNJBG, TACNA
}

\author{
LIVE FOOD PRODUCTION FOR RESEARCH IN MARINE FISHES \\ AQUACULTURE IN UNJBG, TACNA
}

${ }^{1}$ Jordan Ismael Huanacuni Pilco, ${ }^{2}$ Luis Antonio Espinoza Ramos

\begin{abstract}
RESUMEN
La Universidad Nacional Jorge Basadre Grohmann (UNJBG) realiza trabajos de investigación para optimizar las tecnologías de cultivo de la corvina y sargo. La larvicultura constituye un cuello de botella en la producción acuícola. La producción de alimento vivo juega un rol importante en la larvicultura de peces marinos, por ello se desarrolla una investigación en este campo. La finalidad de este trabajo es dar una perspectiva básica de la producción de alimento vivo desarrollado por la UNJBG. Actualmente se produce las microalgas Nannochloris oculata, Isochrysis aff, Galbana var, Tahitiana y Chaetoceros calcitran.; rotiferos Brachionus plicatilis: Artemia franciscana y experimentalmente se desarrolla el cultivo de copépodos marinos nativos con la intención de insertarlos en la dieta larval. En conclusión, la UNJBG cuenta con las especies básicas y la tecnología para la producción de alimento vivo en la alimentación larvaria de peces marinos.
\end{abstract}

Palabras clave: Alimento vivo, Artemia, copépodo, microalga, rotífero.

\begin{abstract}
Jorge Basadre Grohmann National University (UNJBG) conducts research works to optimize the corvina and sargo cultivation technologies. Larviculture constitutes a bottleneck in aquaculture production. The production of live food plays an important role in the larviculture of marine fish, therefore research is developed in this field. The purpose of this work is to publicize the advances in the production of live food. Currently it produces the microalgae Nannochloris oculata, Isochrysis aff. galbana var. tahitiana and Chaetoceros calcitrans; rotifers Brachionus plicatilis: Artemia franciscana and experimentally develops the culture of native marine copepods with the intention of inserting them into larval diet. In conclusion, the UNJBG has the basic species and technology for the production of live food in the larval diet of marine fish.
\end{abstract}

Keywords: Brine shrimp, copepod, live food, microalgae, rotifer.

\section{INTRODUCCIÓN}

La Universidad Nacional Jorge Basadre Grohmann (UNJBG), a través del proyecto "Investigación y desarrollo de las tecnologías de cultivo de peces marinos de importancia económica: corvina Cilus gilberti y sargo Anisotremus scapularis en la región Tacna" aprobado con Resolución Rectoral N ${ }^{\circ} 3780$ 2014-UNJBG, maneja diversas áreas: reproductores, larvas, alevinaje y juveniles.

Uno de los cuellos de botella en el desarrollo de la acuicultura es la nutrición, fundamentalmente en la etapa larvaria, debido a que allí se presenta una gran cantidad de mortalidad (Lavens y Sorgeloos, 1996); es por ello que un laboratorio destinado a la producción de larvas de peces marinos requiere de un área para la producción constante de alimento vivo, entre plantas (fitoplancton) y animales (zooplancton), el fitoplancton conformado básicamente por las microalgas y el zooplancton por los microcrustáceos. El fitoplancton es necesario para la producción de zooplancton y es la base de la cadena alimenticia (Falkowsky y Raven, 1997; Creswell, 2010).

'Ingeniero Pesquero. Tacna- Perú. E-mail: jordan.92ihp@gmail.com

${ }^{2}$ Facultad de Ciencias. Universidad Nacional Jorge Basadre Grohmann. Tacna- Perú. E-mail: laer54@hotmail.com 
El alimento vivo es la fuente más rica de nutrientes que existe para la alimentación en los primeros estadios de peces, debido a su alto contenido de proteínas, vitaminas, nutrientes y aminoácidos y ácidos grasos (New, 1998); además es microscópico, colorido, móvil, y se mantiene en la columna de agua: caracteristicas atractivas para las larvas de peces y moluscos (Bengtson, 2003; David, 2003; Helm et al., 2004). Los hatcheries usan tradicionalmente como alimento vivo a las microalgas, los rotíferos y Artemia; sin embargo, los dos últimos mencionados son enriquecidos con productos comerciales ricos en ácidos grasos antes de ser suministrados a las larvas de peces (Sorgeloos et al., 2001; Cavalin y Weirich, 2009), incrementando su costo de producción. Según Santhosh et al. (2015), actualmente los países que apuestan por la acuicultura marina vienen desarrollando la tecnología adecuada para la inserción de copépodos marinos en la dieta larvaria de peces, pues no necesitan ser enriquecidos, ya que son una fuente natural de ácidos grasos.

En la actualidad, la Universidad Nacional Jorge Basadre Grohmann (UNJBG) cuenta con la implementación básica necesaria para la producción masiva de microalgas, rotiferos, Artemia; y, experimentalmente, se desarrolla el cultivo de copépodos marinos.

El objetivo del presente trabajo es dar a conocer una perspectiva básica del cultivo de alimento vivo para la larvicultura de peces marinos en la región Tacna, a través de los avances desarrollados en la UNJBG.

\section{DESARROLLOTEMÁTICO}

\section{Producción de microalgas}

Hoy existen más de 40 especies de microalgas aisladas y son trabajadas a escala masiva para la acuicultura alrededor del mundo, incluyendo diatomeas.

Las microalgas juegan un rol importante en la acuicultura por el gran valor nutricional que presentan, son indispensables en la producción de cualquier especie marina. El manejo de su cultivo es conocido, pero las modificaciones de los parámetros de cultivo: intensidad de luz, aireación, nutrientes, fotoperiodo, salinidad, etc. influyen en la composición nutricional de las microalgas, alterando los porcentajes de proteinas, aminoácidos, carbohidratos, ácidos grasos, entre otros (Tripathi et al., 2002).

En la UNJBG se cultivan tres especies de microalgas: Nannochloris oculata, Isochrysis aff. Galbana var. Tahitiana y Chaetoceros calcitrans.

N. oculata es utilizada para la masificación de rotiferos y la técnica del agua verde para las unidades de cultivos de larvas de peces. El cultivo de microalgas inicia desde cepa o cultivo stock escalonadamente hasta llegar a cultivo masivo.
El cultivo stock se obtiene a partir del aislamiento de una especie de microalgas, es un cultivo puro mantenido en placas de petri con agar o en tubos de ensayo con medio de cultivo líquido.

El cultivo inicial se lleva a cabo en matraces de 100 y $250 \mathrm{ml}$ con medio de cultivo líquido, sin agitación, a 15 ${ }^{\circ} \mathrm{C}$, irradiancia de 1000 lux y fotoperiodo 24:0. (figura 1)

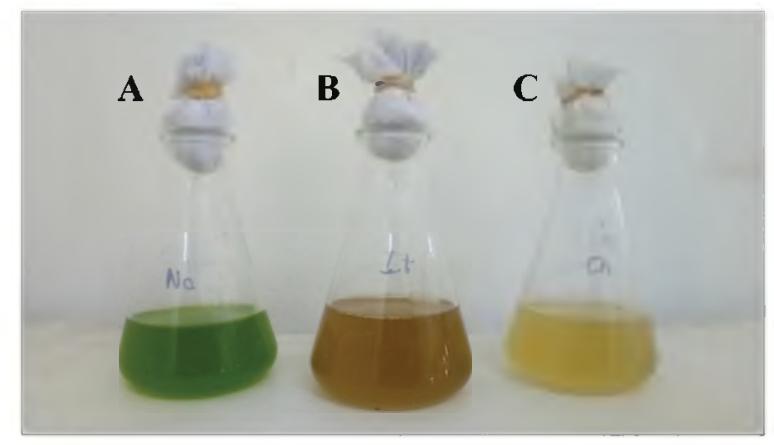

Figura 1. Cultivo inicial de microalgas: (A) Nannochloris oculata, (B) Isochrysis aff. Galbana var. Tahitiana y (C) Chaetoceros calcitrans.

Fuente: Imágenes propias.

El cultivo intermedio se realiza en matraces de 1 a 2 litros con medio de cultivo liquido, con las mismas condiciones.

El cultivo masivo se realiza con la finalidad de obtener grandes cantidades de volumen en un corto período; se lleva a cabo en tanques columnares transparentes de fibra de vidrio con agua de mar UV, aireación vigorosa, adición de nutrientes y fotoperiodo natural expuesto al sol.

El cultivo stock inicial e intermedio de microalgas se realiza con el medio Guillard f/2 (Guillard, 1975) y el cultivo masivo, con el nutriente foliar BAYFOLAN. Se realiza el conteo al cultivo masivo para evaluar la producción diaria con una cámara de Neubauer, según Arredondo y Voltolina (2007).

\section{Producción de rotiferos}

El rotífero es considerado como el organismo más amigable para la producción de biomasa en acuicultura (Tamaru et al., 1991). Es una fuente alimenticia muy importante e indispensable para larvas de peces marinos, debido en parte a su tamanio pequeño; el cual es generalmente inferior al tamaño de boca abierta de larva de peces en edades de 0 a 45 días (Snell y Carrillo, 1984). Los rotiferos son filtradores no selectivos, por ello, son utilizados como vectores alimenticios: tal caracteristica permite modificar el contenido nutricional de los rotíferos usando diferentes microalgas o emulsiones. 


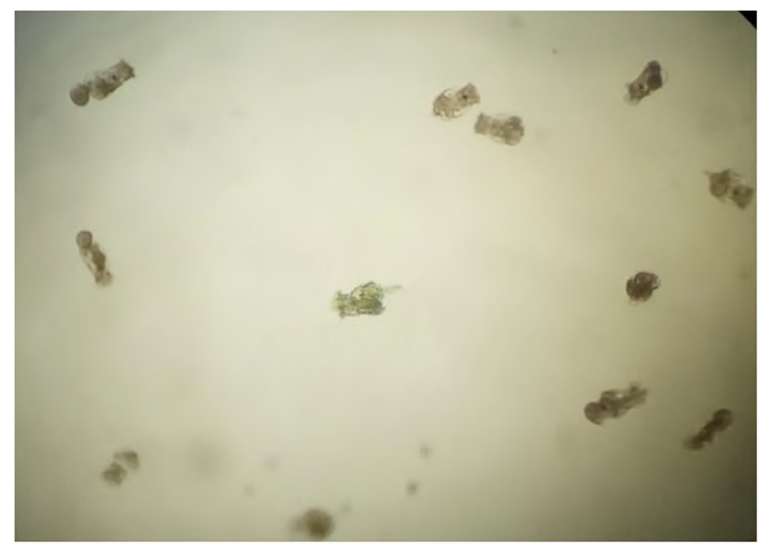

Figura 2. Rotifero Brachionus plicatilis (Estereoscopio 20x).

Fuente: Imágenes propias.

Existen tres cepas principales de rotíferos que son usadas en hatcheries: una cepa pequefia o súper pequeña; Brachiomus tipo S o SS $(50-100 \mu \mathrm{m})$; mediana SM $(100$ a $200 \mu \mathrm{m}) ; 0$ larga $\mathrm{L}(200-300 \mu \mathrm{m})$. El uso de estas puede ser solas o combinadas.

En la UNJBG se cultiva el rotifero Brachionus plicatilis (figura 2), su producción requiere de un cultivo stock, necesario para iniciar la producción de cultivos masivos de rotíferos. El cultivo stock inicia con $20-30 \mathrm{rot} / \mathrm{ml} \mathrm{y}$ termina con $100-120 \mathrm{rot} / \mathrm{ml}$, alimentados con microalgas. Los rotíferos son contenidos en matraces de 21 a $25^{\circ} \mathrm{C}$, fotoperiodo de 24:0, sin aireación y es renovado cada inicio de mes.

Los matraces de 21 son escalados a botellas transparentes de 201 , el cultivo inicia con una concentracion de $50 \mathrm{rot} / \mathrm{ml}$ y termina con $150-200$ $\mathrm{rot} / \mathrm{ml}$, alimentados con microalgas, mantenidos a una temperatura no superior a $30^{\circ} \mathrm{C}$, salinidad de 25 ups y sin aireación.

La producción masiva de biomasa es llevada a cabo en tanques de fibra de vidrio traslúcido de 5001 de volumen funcional, la densidad inicial de cultivo es $\mathbf{5 0}$ $\mathrm{rot} / \mathrm{ml}$ y se registra concentraciones que llegan a superar los $350 \mathrm{rot} / \mathrm{ml}$. La microalga Nannochloris oculata y levadura de pan $\left(0,4 \mathrm{~g} / 10^{6}\right.$ rotíferos) son usadas como alimento para la producción de biomasa de rotíferos; el cultivo es mantenido a 16 ups de salinidad, fotoperiodo de $24: 0,28^{\circ} \mathrm{C}$ de temperatura y aireación moderada. La producción diaria es evaluada, tomando una alicuota de la unidad de cultivo y realizando un conteo con la cámara de Sedgewick-rafter.

El rotífero es enriquecido con una emulsión de ácidos grasos SELCO $\left(0,26 \mathrm{~g} / 10^{6}\right.$ rotiferos) de la marca INVE, antes de ser consumidos por las larvas de peces.

\section{Producción de Artemia franciscana}

La Artemia es un alimento vivo de excelentes características, utilizado en la acuicultura y acuariofilia por su tamafio y el gran valor nutricional de sus nauplios recién eclosionados, por ello son ampliamente utilizados en hatcheries de peces y otras especies cultivables para suplir los requerimientos nutricionales de larvas de peces marinos.

En la UNJBG se trabaja con Artemia franciscana para la alimentación larvaria, posterior a la alimentación con rotíferos. Con el fin de obtener nauplios de Artemia, se compra quistes deshidratados en presentación de 1 libra.

Los quistes de Artemia franciscana son hidratados en agua dulce $(100 \mathrm{~g} / 21)$ con abundante aireación durante una hora, a temperatura ambientecuando los quistes hidratados incrementan su peso a $300 \%$, luego son colectados con un tamiz de $105 \mu \mathrm{m}$, y transferidos a un contenedor con solución decapsuladora a base de hipoclorito de sodio, hidróxido de sodio, agua dulce y agua de mar. Se agita la solución decapsuladora con los quistes durante 3 minutos aproximadamente, se filtran los quistes usando un tamiz de $105 \mu \mathrm{m}$, son enjuagados con abundante agua, trasladados a una solución de tiosulfato para la eliminación de restos de cloro, enjuagados con agua de mar UV y al final con abundante agua dulce para su almacenamiento $o$ incubación.

La eclosión consiste en la incubación de los quistes decapsulados en un contenedor transparente de base cónica con agua de mar ajustada a 25 UPS, con suficiente aireación para mantener los quistes suspendidos y a una temperatura de $36^{\circ} \mathrm{C}$ e irradiancia de 3000 lux. El enriquecimiento se realiza 10 horas antes de la cosecha con la emulsión de ácidos grasos marca SELCO (1g/10 nauplios). La cosecha se realiza según el estadio de Artemia franciscana que requieren las larvas de peces marinos, de acuerdo al diámetro de boca. Una muestra de $1 \mathrm{ml}$ es colocada en una cámara de Sedgewick-rafter para su conteo. La tasa de cosecha óptima corresponde a $90-95 \%$ de eclosión con un aproximado de 300000 nauplios/g.

El cultivo de Artemia franciscana en la UNJBG se está adaptando de manera experimental, por lo que se evalúa las dietas de microalgas aceptables para esta especie a fin de obtener huevos, nauplios y metanauplios y adultos, es decir, Artemia franciscana en todos sus estadios; sin embargo, la producción aún es reducida. (figura 3)

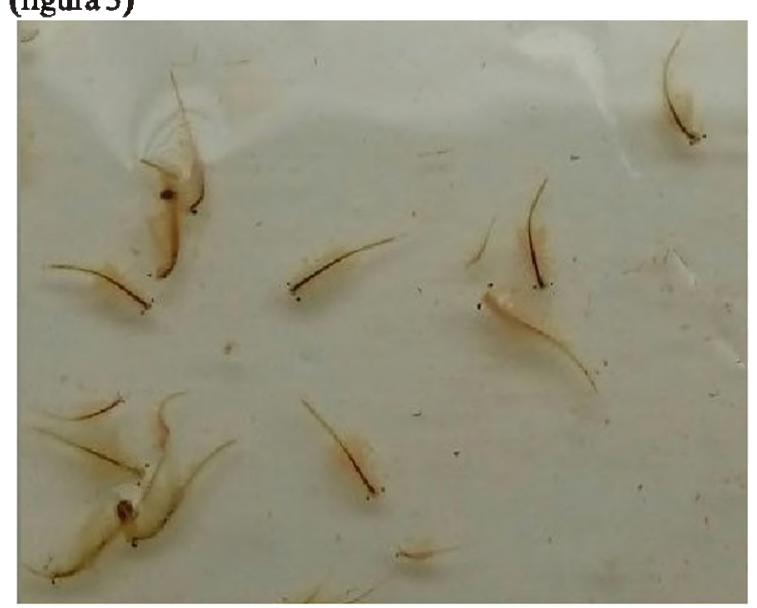

Figura 3. Artemia franciscana adulto.

Fuente: Imágenes propias. 


\section{Copépodos}

Diversos autores dan a conocer los valores nutricionales de los copépodos y el gran potencial de su uso en la acuicultura, afirman que su inclusión por un periodo corto en la dieta larvaria, mejora la supervivencia larvaria, crecimiento, pigmentaciones, reducen las enfermedades, etc.

En la UNJBG se ha planteado la inserción de copépodos nativos como alternativa en la alimentación de larvas de peces marinos (figura 4), actualmente se están identificando diferentes especies, realizando cultivos preliminares con Isochrysis aff. Galbana var. Tahitiana y Chaetoceros calcitrans para seleccionar las que poseen potencial acuícola y puedan ser utilizados en la alimentación larvaria de peces marinos.

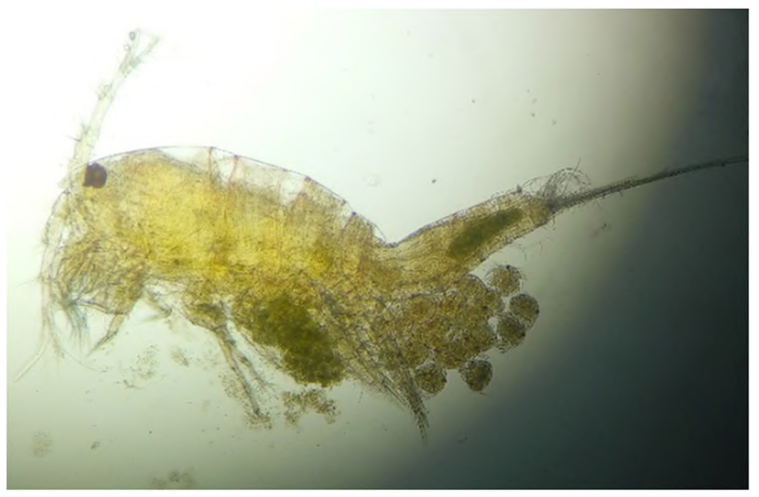

Figura 4. Copépodo hernbra adulta cargada de nauplios, aislado del litoral tacnefio. (Microscopio de luz, 40x)

Fuente: Imágenes propias.

\section{CONCLUSIONES}

La UNJBG cuenta con las especies básicas y la tecnologia para la producción de alimento vivo en la alimentación larvaria de peces marinos, no obstante, aún hay trabajos por realizar en la optimización del cultivo de nuevas especies de zooplancton nativo.

\section{GLOSARIO}

Acuicultura: Actividad que tiene como objetivo la reproducción, crianza, cultivo y comercialización de animales y plantas acuáticas.

Artemia:Crustáceo braquiópodo de aguas hipersalinas, sus huevos pueden enquistarse en condiciones adversas para su desarrollo; los cuales, convenientemente procesados, se almacenan largos periodos y constituyen un alimento ideal para larvas en acuicultura.

Quiste: Forma de resistencia que asumen algunos animales de muy pequeño tamaño, para pasar una determinada época de su ciclo vital o bien para defenderse de las condiciones ambientales adversas.
Copépodo: Crustáceo maxilópodo pequeño, Copepoda, del griego "patas de remo". Conforma gran parte del zooplancton marino. Cosmopolitas.

Cultivo stock: También llamada cepa de microalgas, son mantenidas en medio de cultivo liquido o sólido.

Hatchery: Instalación donde los huevos de peces son incubados a condiciones controladas artificiales.

Microalgas: Microorganismos unicelulares con capacidad de realizar la fotosíntesis.

Nauplio: Primera larva de crustáceos.

Rotífero: Invertebrado microscópico acuático, utilizado como alimento vivo para larvas de diferentes especies en cultivo.

Ups: Unidades prácticas de salinidad o gramos de sal por litro.

\section{REFERENCIAS BIBLIOGRÁFICAS}

Arredondo, B. y Voltolina, D. (2007). Concentración, recuento celular y tasa de crecimiento. En Arredondo y Voltolina (Eds.), Métodos y herramientas analíticas en la evaluación de la biomasa microalgal. México: Centro de Investigaciones Biológicas del Noroeste, s.c. La Paz, B.C.S.

Bengtson, D. (2003). Status of marine aquaculture in relation to live prey: past, present and future. En: Josianne, G. S and Lesley, A. M. (Eds.), Live feeds in marine aquaculture. Blackwell publishing, UK.

Cavalin, F. y Weirich C. (2009). Larval performance of aquacultured Florida pompano (Trachinotus carolinus) fed rotifers (Brachionus plicatilis) enriched with selected commercial diets. Aquaculture, (292) 67-73.

Creswell, L. (2010). Phytoplankton Culture for Aquaculture Feed. Southern Regional Aquaculture Center.

David, A. (2003) Status of marine aquaculture in relation to live prey: past, present and future. En: Live feeds in marine aquaculture Josiannne, G. y Lesley, A. (Eds.) Blackwell publishing, UK.

Falkowski, P. y Raven, J. (2007). Aquatic photosynthesis. Princeton University Press, Princenton.

Guillard, R. (1975). Culture of phytoplankton for feeding marine invertebrates. pp. 29-60 In: Smith, W. and Chanley, H. (Eds.), Culture of Marine Invertebrate Animals. Plenum Press, New York, New York. 
Helm, M, Bourne, N. y Lovatelli, A. 2004. Hatchery Culture of Bivalves: A Practical Manual. FAO Fisheries Technical Paper Number 471. Rome, Italy. 200.

Lavens, P. y Sorgeloos, P. (1996). Manual on the production and use of live food for aquaculture FAO Fisheries Technical Paper. No. 361. Rome, FAO, 295.

New, M. (1998). Global aquaculture: Current trends and challenges for the 21 st century. En: Anans do Aquacultura Brasil. 98(1), 26.

Santhosh, B., Muhammed, F., Unnikrishnan, C. and Anil, M. (2015). Potential species of copepods for marine finfish hatchery. Vizhinjam Research Centre of CMFRI, Vizhinjam

Snell, T. y Carrillo, K. (1984). Body size variation among strains of the rotifer Brachionus plicatilis.Aquaculture 73, 359-367.

Sorgeloos, P., Dhert, P. y Candreva, P. (2001). Use of brine shrimp Artemia spp., in marine fish larviculture. Aquaculture, (200) 147-159.

Tamaru, C., Lee C. y Ako, H. (1991). Improving the larval rearing of stied mullet (Mugil cephalus) by manipulating quantity and quality of the rotifer, Brachionus plicatilis. En Fulks, W. and Main, L. (Eds.). Rotifer and microalgae system. Proceedings of a U.S.-Asia Workshop. Honolulu, Hawai, 89-104.

Tripathi, U., Sarada, R. y Ravishankar, G. (2002). Effect of culture conditions on growth of green alga - Haematococcus pluvialis and astaxanthin production. Acta Physiol. Plant. 24(3), 323-329 